\title{
Design and Implementation of Quality Management Information System in Chi- nese Tobacco Industry Enterprise
}

\author{
Yong Cen, Honglv Wang, Zhihua Zhang, Huanwen Wang \\ Information Center, China Tobacco Zhejiang Industrial Co., Ltd \\ Hangzhou, Zhejiang, 310009, China \\ ceny@zjtobacco.com,wanghl@zjtobacco.com,zzh@zjtobacco.com, \\ wanghw@zjtobacco.com
}

\begin{abstract}
Aim to enhance the level of quality management of tobacco industry enterprise through the construction of information systems. This paper using MVC software design architecture, design the quality management information system for tobacco industry enterprise based on .NET. System use SOA architecture and SAP XI integration bus technology, tight integration with ERP and PDM systems to build a collaborative enterprise quality management environment and to achieve unified management of quality data. Therefore, quality management information system can realize the sharing and transfer the various aspects of quality management and improve the quality of the tobacco industry enterprise management efficiency.
\end{abstract}

Keywords: tobacco industry enterprise; quality management; information system;

\section{Introduction}

Quality management involving almost all aspects of business management, from market, development, design, production, engineering services, and wide-ranging, multi-level, professional, face-to-face management by managers is clearly impossible. In fact, quality management work is through the quality information collection, transmission, processing and feedback to finish. Timely, accurate and comprehensive access to quality information, achieve quality management information is quality guarantee and improve the basis and premise conditions, also reduce the cost and improve the important link of the profits [1]. Previous quality management methods and means have already can't adapt and meets now enterprise quality management of the new requirements, and based on the traditional quality management theory as the basic management information system cannot adapt to the dynamic changes of enterprise environment requirements[2]. Tobacco industry enterprise with information technology and application, development and use quality management information system has is the enterprise information engineering indispensable part [3]. The application of advanced information technology to support quality management information system can break through the traditional quality management in space, time and information processing ability limit [4,5].

This paper presents the design and implementation of a quality management information system based on product data management and enterprise resource planning system collaborative conform to the enterprise quality management stand- 
ards, to realize the quality management system of process management and information management integrated system.

\section{Analysis the demands of system}

Tobacco industry enterprises optimize business management in the construction of the standardization process, with the implementation and application of Enterprise Resource Planning (ERP), Product Data Management (PDM) and Manufacturing Execution System (MES) System, these systems has accumulated a lot of product design data, manufacturing data, quality data, the post-sale service data, etc. From the perspective of process, information systems ineffective integration does not work together to achieve the requirements of collaborative work. From the perspective of quality data, the accumulated quality data lack of a reliable, the latest and most accurate, and the most complete information source management.

Therefore enterprise hope can through the quality management information system construction to solve these problem, these needs can be concluded to the following three aspects:

- Standard, supervise and control the whole process of quality management, and to establish the quality management system for the enterprise quality management information system structure, matching enterprise business process.

- Build distributed data management platform, the enterprise quality management process each link related heterogeneous variety of knowledge and data carrier for the management, and realize the scientific information management, can carry out the corresponding statistical analysis to meet the needs of the enterprise for knowledge management.
- Realize quality information system and other information system data and information of the seamless integration.

\section{Quality management information system design}

\subsection{QMIS architecture design}

Tobacco industry enterprise quality management system use Browse/Server (B/S) model, and based on the enterprise internal Intranet, provide a Web based on the quality information management integration platform. The presentation layer is responsible for user interactive interface, receiving user input; Business logic layer using C\# complete quality information system business logic calculation, IIS as a Web server, through with database established connection, and execute the SQL statement, finally will enforce the results in HTML format transfer to the user browser, quality data and information was kept in Oracle database management. The system can quickly get cigarette product appearance, physical and chemical, and other related quality information and overall quality evaluation results, and in the Web to realize enterprise quality management the whole process management.

\subsection{QMIS framework design}

Quality management information system using Microsoft advanced technology platform .NET and MVC (Model-ViewControl) design pattern, effectively guarantee the systems advanced, expansibility and integration. The software frame design according the business characteristics and enterprise information system integration demand, system structure is divided into the presentation layer, business logic layer and data access and integration layer, that structure is shown as the Figure 1: 


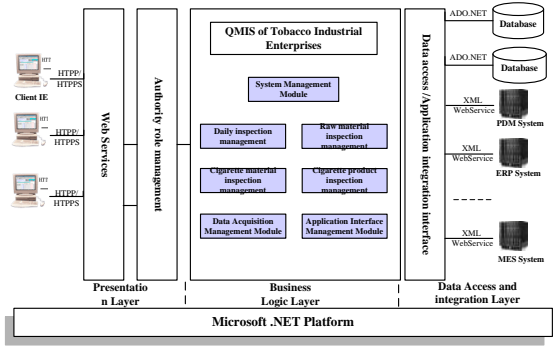

Fig.1The construction structure of QMIS

- Presentation Layer. Quality management information system terminal according to authority information and the browser to realize information input and browse. In the Web server for identity authentication, then use Hypertext Transfer Protocol transfer the information to users.

- Business Logic Layer. Business logic layer mainly for members to provide all kinds of business services. The business logic layer on the one hand responsible for the user's demand response and feedback from the database to get results, and on the other hand, complete web server various kinds of data exchange between infrastructure layers.

- Data Access and Integration Layer. The data access and integration layer include Oracle database, network, operation system, etc. This layer mainly management data access, deal and database management system.

\section{QMIS implementation}

\subsection{The function of QMIS}

According to the demand of tobacco industry enterprise quality management, the system is based on the advanced quality management model from technical design, raw materials procurement, and product processing, quality improvement to the whole process of analysis of information management platform. The system function structure of quality management information platform as shown in Figure 2 shows:

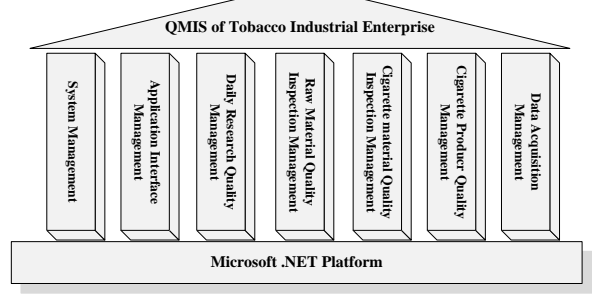

Fig.2 The function structure of QMIS

The interface for cigarette product quality management information system as shown in Figure 3 shows:

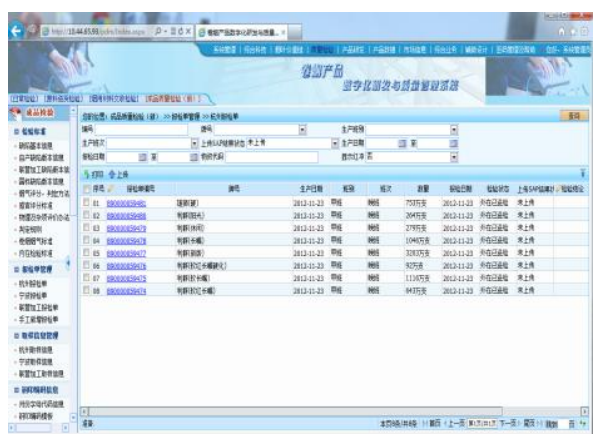

Fig.3 The interface of QMIS

\subsection{QMIS integrate with ERP and PDM}

Enterprise quality management business brought about profound influence and change by the construction of ERP, PDM and MES. In order to improve the overall quality management level, the urgent need to implement QMIS. So construction the quality management information system based on PDM and ERP integration environment, centralized management quality information data, quality management information system and related business system is closely related to set up. 
According to the quality management information system of collaborative business design plan, use Service Oriented Architecture (SOA) technical architecture the SAP XI (Exchange Infrastructure) integration bus technology, to realize QMIS and enterprise resource planning system and product data management system integration [7]. Finally build the system integration technology to realize architecture (Web Service Plan) the main content is as follows Figure 4 shows:

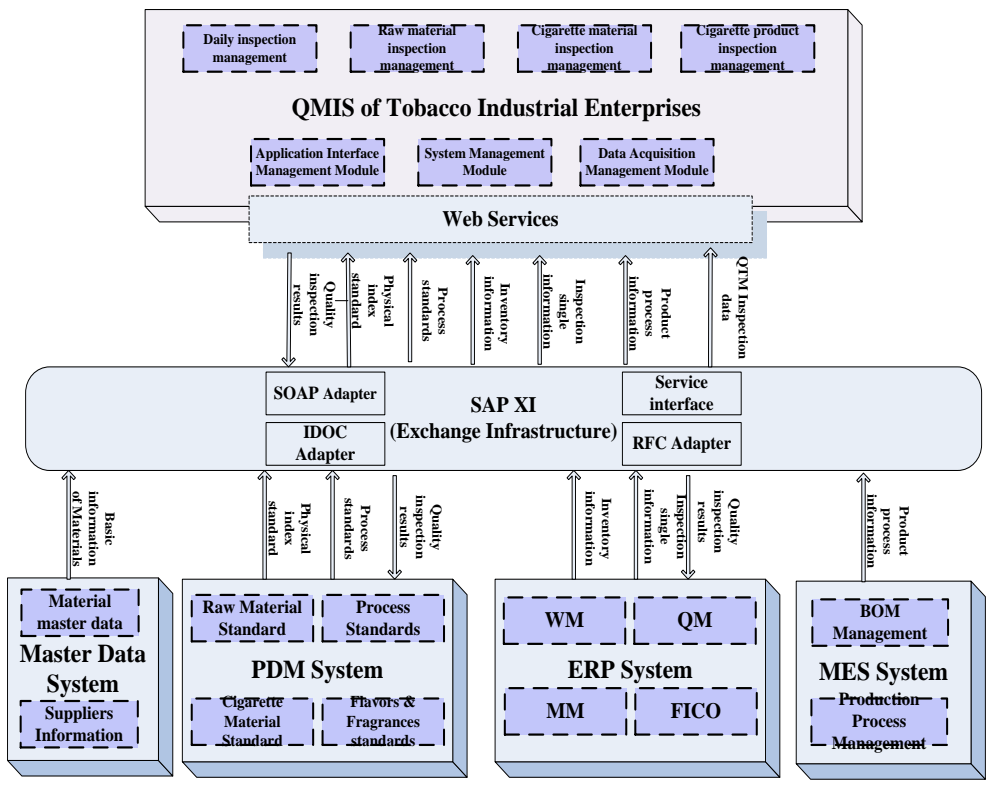

Fig.4 QMIS and other systems information interaction diagram

Specific information interaction between systems as follows:

1) Master data system management the basic information of all materials and suppliers for information system in enterprise. And release basic attribute information about material code, name, etc. to the enterprise each relevant business system.

2) ERP system established different inspection type for different types of material were respectively, and send inspection single to QMIS start the quality inspection work.

3) PDM system release standards of raw material, cigarette material and cigarette product to QMIS, ERP and MES, for the production implementation, cost accounting and quality inspection to provide corresponding standards.
4) QMIS establish and management each quality inspection procedures and quality decision criteria, according to the declaration form and standard information to carry out inspection task, and real-time feedback corresponding quality inspection results information to ERP and PDM system.

5) ERP system according to QMIS feedback quality inspection information, determine whether execution defective goods processing procedure, and according to the final results of the treatment of raw material, cigarette material and cigarette products implement corresponding inventory management operation. 


\subsection{The effects of system implementa- tion}

The implementation of quality management information system oriented total quality management makes realizing enterprise quality management of various nodes information sharing and transfer, also breaking through the traditional quality management in space, in time, and information processing ability limit.

- QMIS optimize the management processes, and introduced in many mature and advanced quality management technology concept.

- QMIS and enterprise ERP, PDM core management information system closely integrated, making total quality management scope expanded, quality audit, quality control, nonconforming product processing and a series of content of enterprise quality management integration level are improved.

- QMIS base on network and database, and with the expert intelligent system theory aid, realizing the system automatically decision and control. Enterprise can analysis and processing product quality information, improve the enterprise quality management level.

\section{Conclusions}

In this paper analysis the tobacco industry enterprise's quality management situation, carding optimize business processes, design and implement based on ERP and PDM system synergistic quality management information system. The system realizes the automation decision for raw material, cigarette material and cigarette product in quality management, will improve the enterprise quality information management work efficiency and support enterprise to provide decision for improve cigarette product quality. System in the future will focus on the introduction of more intelligent methods further enhance system function, using of advanced data mining methods for quality information data analysis and processing, to help further improve enterprise quality management level.

\section{References}

[1] ZENG Fen-Fang,CHEN WanLing,YAN Xiao-Guang. Research and application on quality control system in production process base on PDM[J]. Machinery Design \& Manufacture, 2010, 05(5): 256-257 (in Chinese)

[2] LIU Cai-Yan, SUN You-Fa. Modeling Process Integrated Quality Management System in Manufacturing Enterprises. 2009 Second International Conference on Future Information Technology and Management Engineering, 2009.

[3] Zhou Feng. The Research and Realization of the Quality Management Information System Based on ASP[D]. Wuhan: Huazhong University of Science and Technology, 2004(in Chinese).

[4] CHEN Ke-Yi. Research on Quality Management System Based on Workflow[D]. Harbin: Harbin University of Science and Technology, 2008(in Chinese).

[5] HE Zhen, LU Jin, LIU Xiao- Liang, et al. Design and development of the integrated quality management system IQMS2.0[J] .Industrial Engineering Journal,2007,10(6): $54-58$ (in Chinese).

[6] LU Hai-Liang, ZHANG Zhi-Hua, WANG Huan-Wen. Application of Unified Information Integration Platform in Cigarette Industrial Enterprise Implemented by SAP XI Based on SOA[J]. Tobacco Science \& Technology, 2011,1:29-32(in Chinese) 